\title{
Synergistic Effect of FeNi Bimetallic Clusters for the Catalytic of Hydrogen Dissociation and Desorption: A Density Functional Theory Study
}

\author{
FEI WU ${ }^{1,2 *}$, HAIGANG LI ${ }^{1,2}$, CHEN CHENG ${ }^{1,2}$, HAO ZHANG ${ }^{1,2}$, SHUNXIN FEI $^{3 *}$ \\ ${ }^{1}$ Wuhan Institute of Marine Electric Propulsion, Nanli Road, Wuhan 430064, China \\ ${ }^{2}$ Wuhan Hydrogen Fuel Cell Engineering Research Center, Nanli Road, Wuhan 430064, China \\ ${ }^{3}$ Sustainable Energy Laboratory, Faculty of Materials Science and Chemistry, China University of Geosciences, Wuhan, \\ Lumo Road, Wuhan 430074, China
}

\begin{abstract}
Cognition to the metal-metal interactions is of vital importance for the catalytic process and would help exploring novel catalysts. In the present study, the model system of $\mathrm{Fe}_{x} N i_{y}(x+y=6)$ bimetallic clusters was utilized to study how metal-metal interactions influence the catalytic performance. The formation energies of different FeNi clusters, the hydrogen chemisorption energies together with the maximum hydrogen capacity and the saturated hydrogen atoms desorption energies were calculated. Bimetallic clusters exhibit a superior performance than pure clusters. Especially, $\mathrm{Fe}_{2} \mathrm{Ni}_{4}$ cluster has the highest hydrogen loading capacity, the most facile hydrogen molecule dissociation activation energy barrier and the lowest hydrogen atom desorption energy, suggesting that it is easier to dissociate $\mathrm{H}_{2}$ and release the $\mathrm{H}$ atoms. As a consequence, by adjusting appropriate metal/metal ratios, it is possible to design bimetallic catalysts with excellent catalytic performance.
\end{abstract}

Keywords: Fe-Ni bimetal, catalysis, metal-metal interactions, activity promotion

\section{Introduction}

Transition metals are widely used in catalytic hydrogenation and dehydrogenation applications for their highly efficient catalytic performance [1-4]. VIII family metals, such as Pt, $\mathrm{Pd}, \mathrm{Ru}$ and $\mathrm{Rh}$, are most commonly used catalysts, displays remarkable activity in catalytic hydrogenation of unsaturated organic molecules [5-10]. Despite their high activity, the inherent defects such as the high cost and limited resources greatly limit their large-scale application. Therefore, non-noble metals are attracting more and more attentions. Bimetals, especially those based on non-noble, low-cost, and environmentalfriendly metals, are in massive need for different applications like catalysts [11-13], electrocatalysts [14$16]$, sensors [17-19] and so on in recent years.

The performance of a bimetallic catalyst is often determined by its metal-metal interaction. A metal can be combined with a variety of other metals with specific properties so as to obtain more active sites, such as $\mathrm{Ni}-\mathrm{Fe}[20,21]$, Ni-Co [22,23], and $\mathrm{Ni}-\mathrm{Cu}[11,15]$, the interactions between different metals make these bimetals showing significant improvement in activity. The alloy not only provides stable nanostructure for adsorption sites but also may give rise to the charge rearrangement of the catalyst, thus affect its catalytic performance. Corma et al. synthesized bimetallic nanoparticles of CoNi@C catalyst by one step hydrothermal treatment with glucose assisted, the result showed that the catalytic activity of the obtained bimetal are five times higher than the corresponding monometallic $\mathrm{Co} @ \mathrm{C}$ catalyst on the selective hydrogenation of nitroarenes to corresponding anilines [24]. Especially, they found that $\mathrm{H}_{2}$ chemisorption dissociation is the rate controlling step in the whole process. Another study on the NiFe@Cu hydrogen evolution catalyst showed that bimetal has a high activity in the catalytic conversion and selectivity [25]. Indeed, those studies have greatly promoted the development of morphology control of bimetallic nanoparticles, the theoretical study of the reaction mechanism is rare, and cluster level insight would further promote the catalytic performance, especially in the atomic catalysis.

\footnotetext{
*email:polymer0705@163.com,Shunxin_Fei@163.com
} 
The catalytic efficiency of hydrogenation reaction is extremely rely on how facile a hydrogen molecule dissociates and how quick a hydrogen atom escape from the catalyst surface. Ni clusters have been systematically studied, the results showed that $\mathrm{Ni}$ clusters have a superior $\mathrm{H}$ adsorption ability than other non-noble transition metal clusters [26-28]. These researches primarily focus on the structures stability, charge distribution [29-31], and the crystal growth process [32]. Yet, the reaction mechanism of hydrogen dissociation on Ni-based bimetallic catalysts with different components have not been systematically studied. Therefore, we combine Fe with $\mathrm{Ni}$ to form a series of FeNi clusters to perform DFT calculations on the changes in various important properties of the clusters. Although the microstructures and properties of a realistic FeNi nanoparticle are more complicated, the FeNi clusters are still set to a given sub-nano size. For certain studies have already proved that a cluster consist of more than six atoms may systematically demonstrate the catalytic reaction process sufficiently to offer helpful insights into metal-metal interactions [33-35].

In this work, we try to understand how metal-metal interactions influence the catalytic activity of a bimetal. $\mathrm{Fe}_{x} \mathrm{Ni}_{y}$ bimetallic clusters $(x+y=6)$ were used to represent the model system. DFT were utilized to systematically simulate the whole catalytic process of hydrogen on $\mathrm{Fe}_{x} \mathrm{Ni}_{y}$ bimetallic clusters. The vital properties, including the average formation energies, the hydrogen chemisorption energies, the activation energies of $\mathrm{H}_{2}$ dissociation on different clusters, hydrogen atoms desorption energies, as well as the $\mathrm{H}$ capacity of the clusters are systematically studied. Our findings provide an useful insight into the interactions between different metals for the promoted catalytic behavior on the dissociation and desorption of hydrogen and shed light on the design of noble metal free bimetallic catalysts.

\section{Materials and methods \\ Surface model and computational methods}

All simulations were carried out by utilizing DFT/GGA with the PBE exchange-correlation functional as performed in the $\mathrm{DMol}^{3}$ package [36,37]. All the electronic structure of different FeNi clusters were simulated by utilizing a spin-polarization pattern to address the open shell systems. In order to illustrate the valence electrons and the core electrons, the DNP basis set and an effective core potential were chosen [38,39]. A previous study proved that the basis set of this type will lead to ignorable superposition effects [40]. All configurations were totally optimized, the charge distribution and transfer were carried out by employing the Mulliken population analysis [40]. The Tkatchenko and Scheffler method was used to evaluate the effect of dispersion correction for the adsorption and desorption of hydrogen atoms on the clusters, and the results showed that it is ignorable [41]. To obtain perception into the kinetics barriers of hydrogen molecule chemisorption dissociation, the transition state (TS) search for hydrogen molecule on $\mathrm{Fe}_{6}, \mathrm{Ni}_{6}$ and $\mathrm{Fe}_{2} \mathrm{Ni}_{4}$ cluster were conducted using LST/QST method [42]. Normal mode analysis with an imaginary frequency was used to confirm the transition state structure.

The equation of the average formation energy $\left(\Delta E_{\mathrm{FE}}\right)$ for $\mathrm{Fe}_{x} \mathrm{Ni}_{y}$ cluster is computed by utilizing

$$
\Delta E_{(\mathrm{FE})}=\left[x E(\mathrm{Fe})+y E(\mathrm{Ni})-E\left(\mathrm{Fe}_{x} \mathrm{Ni}_{y}\right)\right] /(x+y)
$$

where $E(\mathrm{Fe}), E(\mathrm{Ni})$ and $E\left(\mathrm{Fe}_{x} \mathrm{Ni}_{y}\right)$ are the energies of the $\mathrm{Fe}, \mathrm{Ni}$ and the $\mathrm{Fe}_{x} \mathrm{Ni}_{y}$ clusters, respectively.

The different chemisorption energies of hydrogen molecule on $\mathrm{Fe}_{x} \mathrm{Ni}_{y}$ clusters were calculated by the following equation

$$
\Delta E(\mathrm{CE})=2\left[E\left(\mathrm{Fe}_{x} \mathrm{Ni}_{y}\right)+n / 2 E\left(\mathrm{H}_{2}\right)-E\left(\mathrm{Fe}_{x} \mathrm{Ni}_{y} \mathrm{H}_{n}\right)\right] / n
$$

where $E\left(\mathrm{Fe}_{x} \mathrm{Ni}_{y} \mathrm{H}_{n}\right), E\left(\mathrm{H}_{2}\right)$ and $n$ represent the energy of $\mathrm{Fe}_{x} \mathrm{Ni}_{y}$ cluster absorbed with hydrogen, the energy of an hydrogen molecule and the number of hydrogen atoms absorbed on the cluster, respectively.

The realistic catalytic hydrogenation procedure is always completed under the condition of a certain hydrogen pressure where $\mathrm{H}$ coverage reach saturation or oversaturation on the catalyst surface. Hence, 
it is necessary to calculate the desorption energy of $\mathrm{H}$ atom from the catalyst with hydrogen saturated adsorption to assess its catalytic activity. It is noted that hydrogen atoms prefer to desorb consecutively. Here, the desorption energies of the $\mathrm{Fe}_{x} \mathrm{Ni}_{y}$ clusters with hydrogen atoms fully covered were calculated by employing the equation below

$$
\Delta E_{(\mathrm{DE})}=E(\mathrm{H})-\left[E\left(\mathrm{Fe}_{x} \mathrm{Ni}_{y} \mathrm{H}_{m}\right)-E\left(\mathrm{Fe}_{x} \mathrm{Ni}_{y} \mathrm{H}_{m-2}\right)\right] / 2
$$

where $E(\mathrm{H})$ represents the total energy of the hydrogen atom and $m$ represents the hydrogen atoms number that is in saturated adsorption. Besides, AIMD calculations under $298.15 \mathrm{~K}$ were carried out on the $\mathrm{Fe}_{x} \mathrm{Ni}_{y}$ clusters with hydrogen atoms fully covered for $3 \mathrm{ps}$ in a NVT canonical ensemble utilizing the Nose-Hoover thermostat $[43,44]$ for temperature regulate. When running the Molecular Dynamics, superfluous hydrogen atoms absorbed on the cluster will recombine to generate hydrogen molecules, which lead to a weak association with the cluster [45].

\section{Results and discussions}

The purpose of this study is to understand how metal-metal interaction affect the catalytic performance of a bimetallic catalyst. Previous studies on pure Ni, Pd and Pt clusters showed that the variability of average formation energy is relatively small after the number of atoms in a cluster exceeds six [26]. Hence, the atom number of the model system $\mathrm{Fe}_{x} \mathrm{Ni}_{y}$ cluster was set to six. Considering the various isomeric structures for different $\mathrm{Fe}_{x} \mathrm{Ni}_{y}$ clusters for a given cluster size. In order to confirm the most stable configuration of a $\mathrm{Fe}_{x} \mathrm{Ni}_{y}$ cluster, massive structural optimizations were carried out to acquire the structure with lowest energy. The Mulliken charge analysis and the average formation energies of different $\mathrm{Fe}_{x} \mathrm{Ni}_{y}$ clusters with the most stable structures are shown in Figure 1. The results suggest that the average formation energies of $\mathrm{Fe}_{x} \mathrm{Ni}_{y}$ bimetallic clusters rises with the number of $\mathrm{Ni}$ atom increases, and $\mathrm{Fe}_{1} \mathrm{Ni}_{5}$ has the highest average formation energy of $2.33 \mathrm{eV}$. Clearly, FeNi clusters tend to be more stable than $\mathrm{Fe}_{6}$ and $\mathrm{Ni}_{6}$ pure clusters. The Mulliken charge analyses show that $\mathrm{Fe}$ atoms have lower electron density than that of $\mathrm{Ni}$ atoms due to the charge transfer from $\mathrm{Fe}$ atoms to adjacent $\mathrm{Ni}$ atoms, which is well agreed with the truth that $\mathrm{Ni}$ (1.91) has a relatively higher electronegativity than $\mathrm{Fe}(1.83)$. All the $\mathrm{Ni}$ atoms display negative charge in the FeNi bimetallic clusters. As the number of Ni atom increases, the charges each $\mathrm{Ni}$ atom can share undergoing a trend from rising to decreasing. The $\mathrm{Fe}$ atoms, on the contrary, continuously losing charges with the charge value increases from 0 to positive 0.308. Therefore, we can conclude that the charge redistribution on the clusters and the increased stability of $\mathrm{Fe}_{x} \mathrm{Ni}_{y}$ clusters may have an important impact on the interaction between hydrogen and $\mathrm{Fe}_{x} \mathrm{Ni}_{y}$ clusters.

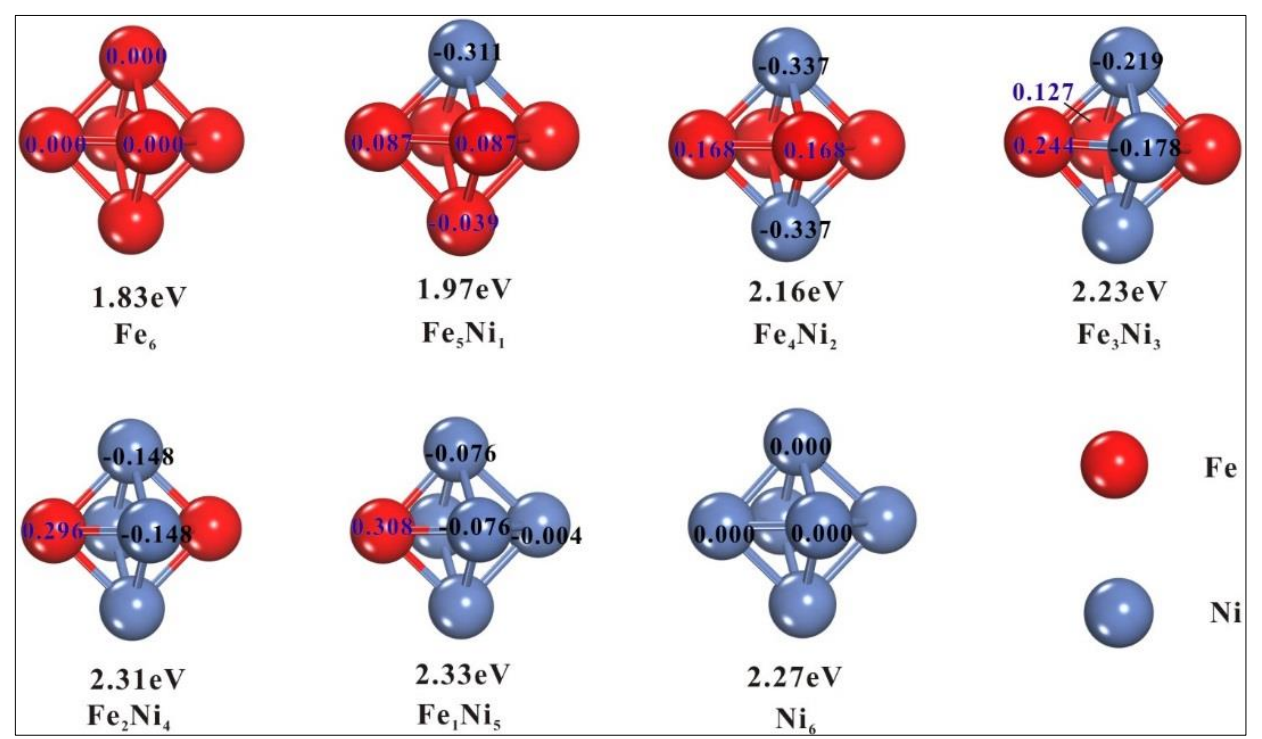

Figure 1. The average formation energies and the Mulliken charge distribution of the optimized lowest energy structures of the $\mathrm{Fe}_{x} \mathrm{Ni}_{y}$ clusters $(x+y=6)$. Red: Fe atoms; Blue: $\mathrm{Ni}$ atoms 
The structures of $\mathrm{Fe}_{x} \mathrm{Ni}_{y}$ clusters with the largest formation energy were selected among their isomers to study the chemisorption process of hydrogen. Initially, a $\mathrm{H}_{2}$ molecule moves to the top position of a $\mathrm{Fe}_{x} \mathrm{Ni}_{y}$ cluster. In general, there are two adsorption sites (the top sites of $\mathrm{Fe}$ and $\mathrm{Ni}$ atom) that can hold a $\mathrm{H}_{2}$ molecule. Figure 2 shows the chemisorption structures with the lowest energy and dissociation chemisorption energies of $\mathrm{H}_{2}$ on $\mathrm{Fe}_{x} \mathrm{Ni}_{y}$ clusters. The $\mathrm{H}-\mathrm{H}$ bond is activated on the adsorption site in each cluster, this makes it become longer. Udrea et al. [46] reported that the formation of FeNi alloy could favor the activation of $\mathrm{H}_{2}$ and facilitate the generation of new active surface species. According to the calculation results, we can learn that the dissociation chemisorption energies vary with the change in the components ratio. Obviously, the chemisorption energies of $\mathrm{Fe}_{x} \mathrm{Ni}_{y}$ clusters are higher than their corresponding pure $\mathrm{Fe}$ and $\mathrm{Ni}$ clusters, indicating that hydrogen molecules prefer to adsorb on $\mathrm{Fe}_{x} \mathrm{Ni}_{y}$ bimetallic clusters and can be readily dissociated into hydrogen atoms.

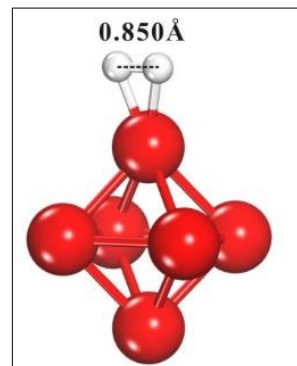

$0.28 \mathrm{eV}$

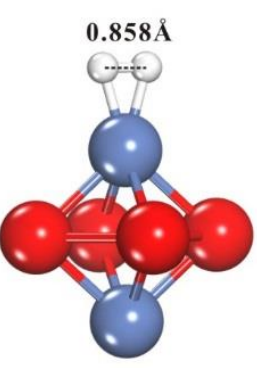

$1.23 \mathrm{eV}$

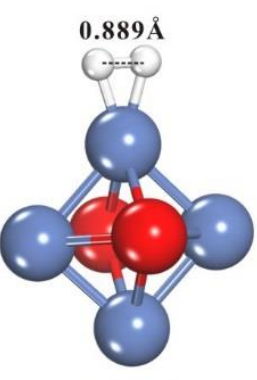

$0.55 \mathrm{eV}$

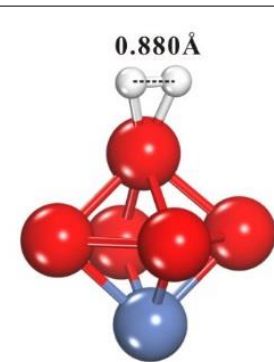

$0.31 \mathrm{eV}$

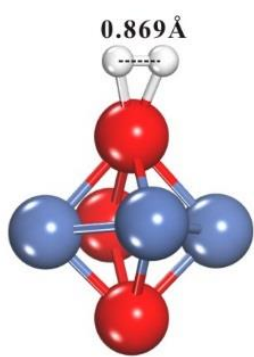

$0.54 \mathrm{eV}$

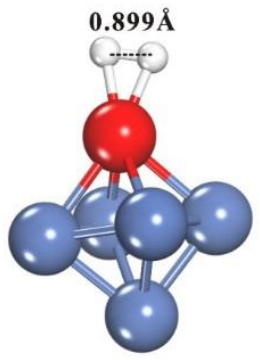

$0.48 \mathrm{eV}$

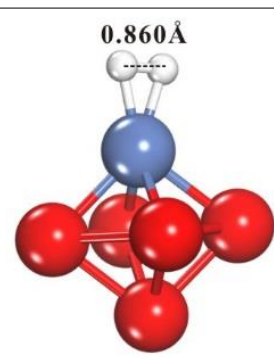

$0.38 \mathrm{eV}$

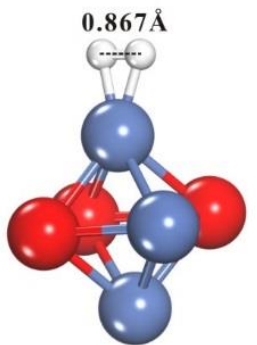

$0.33 \mathrm{eV}$

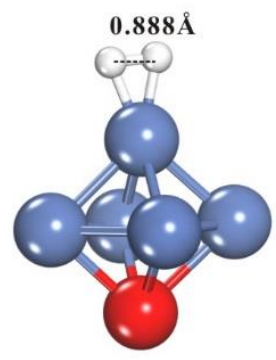

$0.72 \mathrm{eV}$

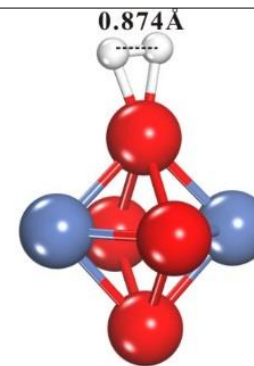

$1.16 \mathrm{eV}$

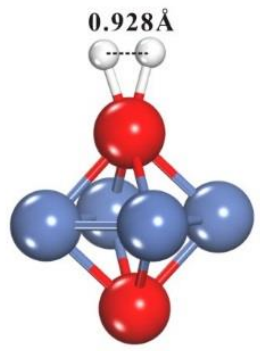

$0.40 \mathrm{eV}$

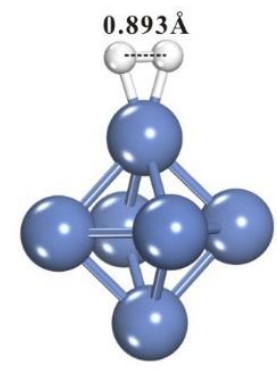

$0.27 \mathrm{eV}$

Figure 2. Optimized hydrogen adsorption configurations and corresponding chemisorption energies of different $\mathrm{Fe}_{\mathrm{x}} \mathrm{Ni}_{\mathrm{y}}$ clusters. White: $\mathrm{H}$ atoms

Despite the chemisorption process of a hydrogen molecule on $\mathrm{Fe}_{x} \mathrm{Ni}_{y}$ cluster is exothermic, the equilibrium structure is still not achieved. After overcome the dissociation energy barrier, $\mathrm{H}$ atoms always prefer to diffuse to the nearby octahedral edges. The detailed analyses of the $\mathrm{H}_{2}$ dissociation energy barriers on octahedral $\mathrm{Ni}_{6}, \mathrm{Fe}_{6}, \mathrm{Fe}_{2} \mathrm{Ni}_{4}-\mathrm{N}$ (Ni top site) and $\mathrm{Fe}_{2} \mathrm{Ni}_{4}-\mathrm{F}$ (Fe top site) clusters are shown in Figure 3. $\mathrm{A} \mathrm{H}_{2}$ molecule adsorbs on the top site of the $\mathrm{Ni}_{6}$ cluster and is dissociated into two $\mathrm{H}$ atoms after overcome an energy barrier of $0.42 \mathrm{eV}$. This give rise to the two hydrogen atoms diffuse 
to two opposite octahedral edges with an reaction energy of minus $1.10 \mathrm{eV}$. Meanwhile, the same process on $\mathrm{Fe}_{6}$ cluster needs surpass a higher energy barrier of $1.01 \mathrm{eV}$, and result in the two $\mathrm{H}$ atoms spread to two opposite edges with an reaction energy of minus $1.15 \mathrm{eV}$. Apparently, the $\mathrm{H}_{2}$ dissociation becomes easier on $\mathrm{Fe}_{2} \mathrm{Ni}_{4}$ cluster, for the energy barrier tend to be more moderate for $\mathrm{Fe}_{2} \mathrm{Ni}_{4}-\mathrm{N}(0.36 \mathrm{eV})$ and $\mathrm{Fe}_{2} \mathrm{Ni}_{4}-\mathrm{F}(0.40 \mathrm{eV})$. Notably, this result is similar to our previous work [47] on the interaction between $\mathrm{Pd}$ cluster and support, that the charge redistribution will give rise to the decrease of $\mathrm{H}_{2}$ dissociation activation energy and the increase of the catalytic activity.

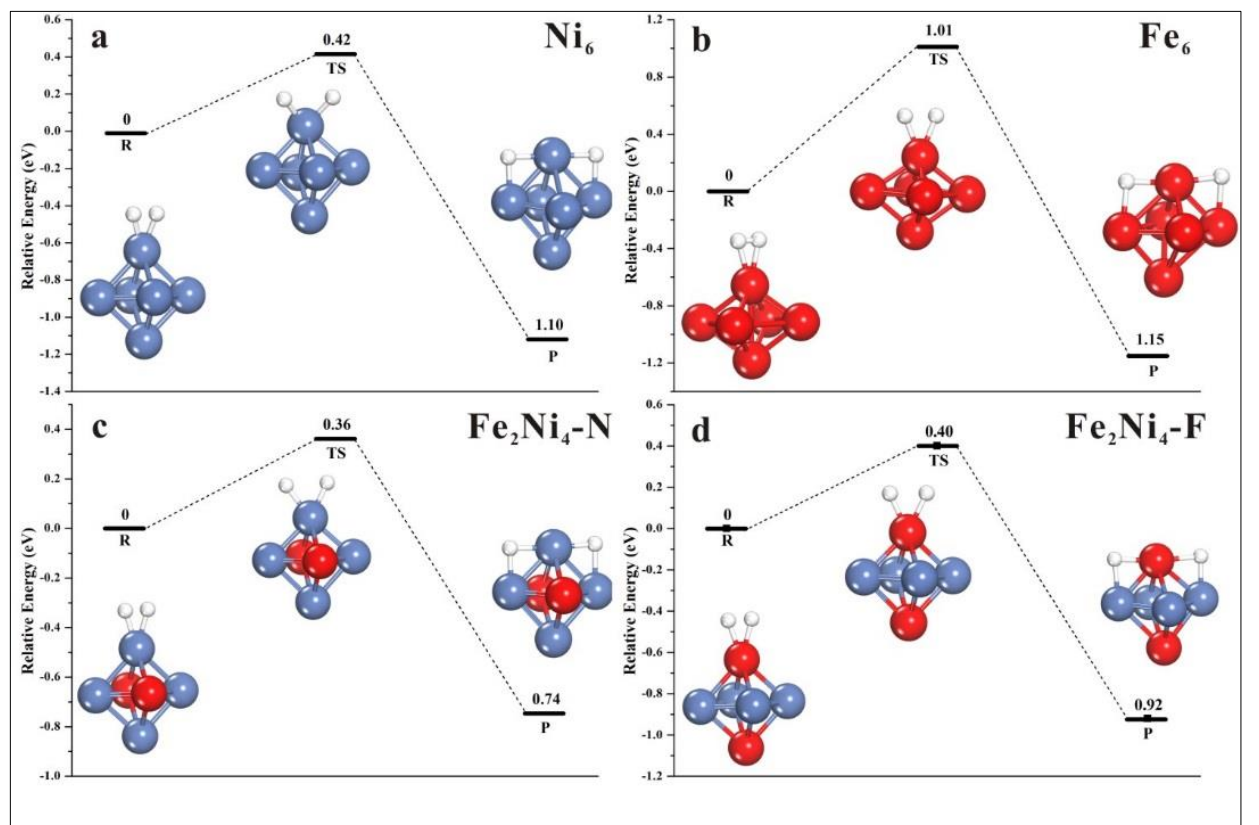

Figure 3. Simulated reaction pathway of hydrogen dissociative chemisorption on the top site of a) $\mathrm{Ni}_{6}$ pure cluster, b) $\mathrm{Fe}_{6}$ pure cluster, c) Ni top site of $\mathrm{Fe}_{2} \mathrm{Ni}_{4}$ and d) $\mathrm{Fe}$ top site of $\mathrm{Fe}_{2} \mathrm{Ni}_{4}$ octahedral cluster

Except for the $\mathrm{H}_{2}$ dissociation chemisorption energy, the desorption energy of a hydrogen atom on a cluster with hydrogen fully covered is also an extremely important indicator for assessing the catalytic activity. Hence, we conducted the successive loading of hydrogen atoms to see the hydrogen capacity of the FeNi clusters. Generally, during the hydrogen dissociative chemisorption process, hydrogen atoms prefer to adsorb on the edge sites than the hollow sties. As the H loading amount increases, some active top sites of the clusters are also occupied by the extra hydrogen atoms. Subsequently, AIMD runs were performed at $298.15 \mathrm{~K}$ to make sure that all the hydrogen atoms are in the state of chemisorption. The radial distribution of $\mathrm{H}-\mathrm{H}$ bond length of $\mathrm{Fe}_{2} \mathrm{Ni}_{4}-\mathrm{H}_{18}$ and $\mathrm{Fe}_{2} \mathrm{Ni}_{4}-\mathrm{H}_{16}$ clusters is shown in Figure 4. The curve of $\mathrm{Fe}_{2} \mathrm{Ni}_{4}-\mathrm{H}_{18}$ cluster displays a intensive peak close to $0.7 \AA$, suggesting that at least one hydrogen molecule is formed due to the oversaturation of $\mathrm{H}$ atoms. On the other side, a strong peak of $\mathrm{Fe}_{2} \mathrm{Ni}_{4}-\mathrm{H}_{16}$ is emerged near $2.3 \AA$, implying that all the hydrogen atoms are well separated. Apparently, the maximum saturated adsorption of hydrogen atoms is 16 for $\mathrm{Fe}_{2} \mathrm{Ni}_{4}$ cluster. Considering the contributions of entropic and to further confirm the AIMD results, the Gibbs free energies for the formation of $\mathrm{Fe}_{2} \mathrm{Ni}_{4}-$ $\mathrm{H}_{18}\left(\mathrm{Fe}_{2} \mathrm{Ni}_{4}+9 \mathrm{H}_{2} \rightarrow \mathrm{Fe}_{2} \mathrm{Ni}_{4}-\mathrm{H}_{18}\right)$ and $\mathrm{Fe}_{2} \mathrm{Ni}_{4}-\mathrm{H}_{16}\left(\mathrm{Fe}_{2} \mathrm{Ni}_{4}+8 \mathrm{H}_{2} \rightarrow \mathrm{Fe}_{2} \mathrm{Ni}_{4}-\mathrm{H}_{16}\right)$ clusters at $298.15 \mathrm{~K}$ were also calculated. It is found that the value of $\Delta \mathrm{G}$ is $-18.3 \mathrm{kcal} / \mathrm{mol}$ for $\mathrm{Fe}_{2} \mathrm{Ni}_{4}-\mathrm{H}_{16}$ and it increases to $6.9 \mathrm{kcal} / \mathrm{mol}$ after two extra hydrogen atoms are loaded, confirming that the adsorption of 16 hydrogen atoms is the maximum capacity for the $\mathrm{Fe}_{2} \mathrm{Ni}_{4}$ cluster.

Figure 5 shows the fully optimized structures of FeNi clusters with hydrogen adsorption saturated and the corresponding desorption energies. Compare to $\mathrm{Fe}_{6}, \mathrm{Ni}_{6}$, and other $\mathrm{Fe}_{x} \mathrm{Ni}_{y}$ clusters which can hold only 14 hydrogen atoms, $\mathrm{Fe}_{2} \mathrm{Ni}_{4}$ has the highest hydrogen capacity of 16 . 


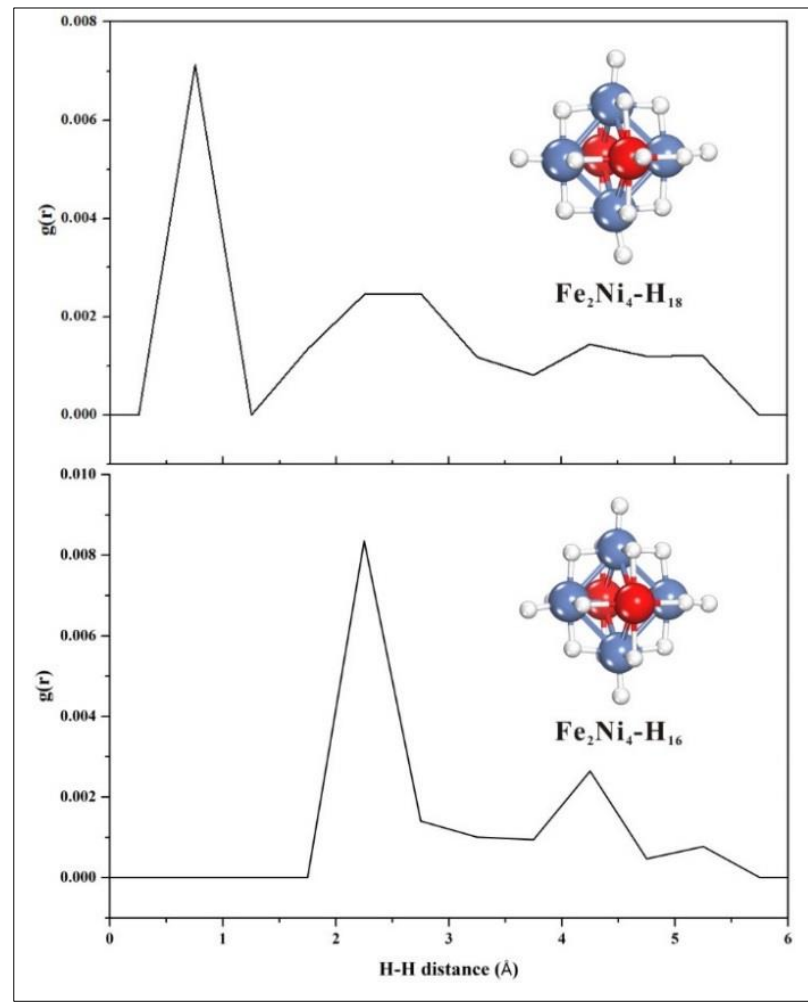

Figure 4. Simulated $\mathrm{H}-\mathrm{H}$ distance distribution of $\mathrm{Fe}_{2} \mathrm{Ni}_{4}-\mathrm{H}_{18}$ and $\mathrm{Fe}_{2} \mathrm{Ni}_{4}-\mathrm{H}_{16}$ clusters. $\mathrm{g}(\mathrm{r})$ was gained by tabulating all the data of $\mathrm{H}-\mathrm{H}$ distances at every step of the AIMD trajectories fit with Gaussian functions

After the dissociative hydrogen atoms occupied all the 12 edges of the octahedral $\mathrm{Fe}_{2} \mathrm{Ni}_{4}$ clusters, four more opposite top sites of $\mathrm{Ni}$ will be available for extra four hydrogen atoms. The desorption energies $\Delta E_{(\mathrm{DE})}$ of $\mathrm{Fe}_{x} \mathrm{Ni}_{y}$ clusters in the hydrogen adsorption saturated state vary in a range of $1.99 \mathrm{eV}$ to $2.25 \mathrm{eV}$. Apparently, the combination of $\mathrm{Fe}$ and $\mathrm{Ni}$ as well as the rearrangement of charge with an appropriate ratio would help raising the hydrogen atoms adsorption amount and make the hydrogen atom become easier to escape from the $\mathrm{Fe}_{x} \mathrm{Ni}_{y}$ clusters.

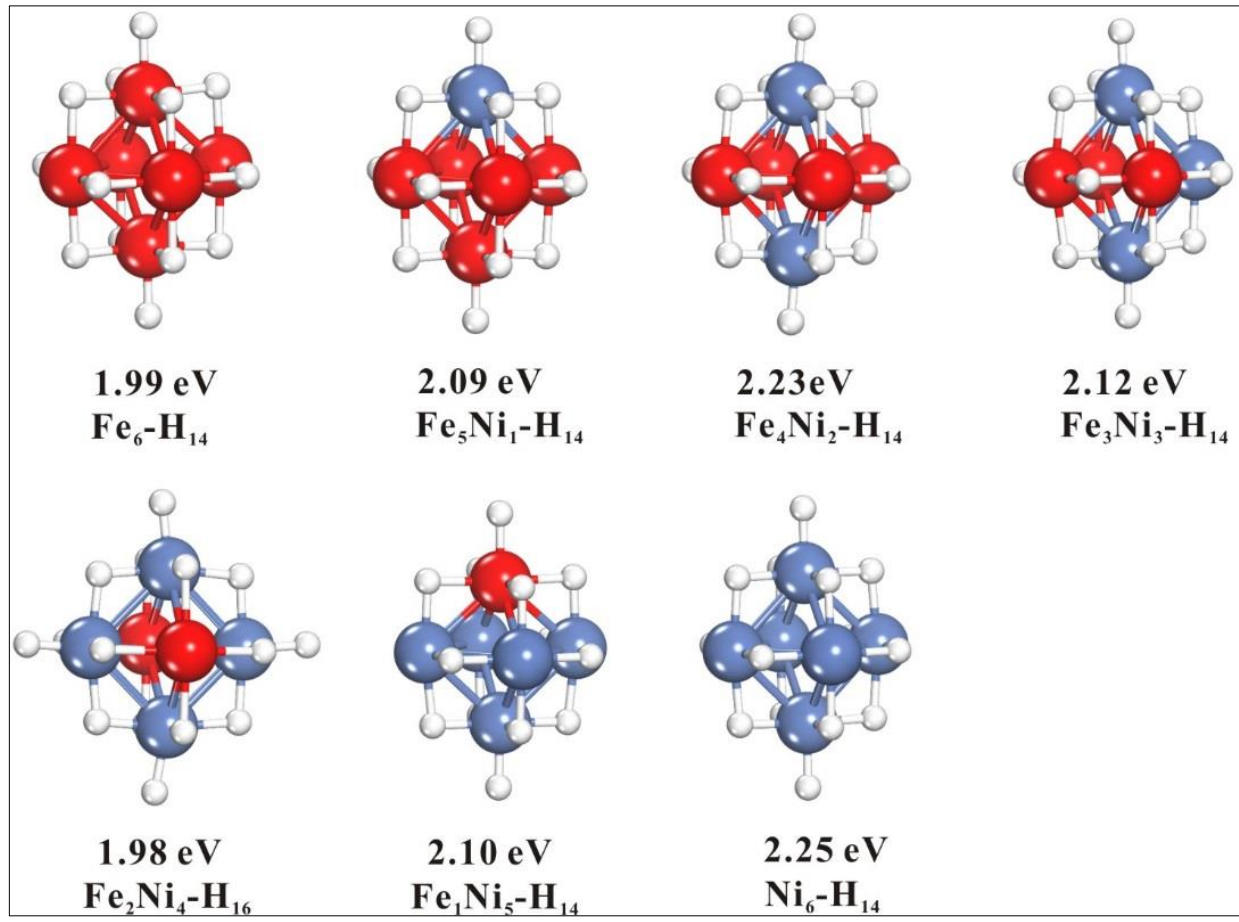

Figure 5. Optimized structures of the $\mathrm{Fe}_{x} \mathrm{Ni}_{y}$ clusters with hydrogen atoms fully covered and the desorption energy to release a hydrogen atom in the saturation state 
Table 1. The average metal-H bond length of the $\mathrm{Fe}_{x} \mathrm{Ni}_{y}$ clusters

\begin{tabular}{|c|c|c|}
\hline \multirow{2}{*}{ Models } & \multicolumn{2}{|c|}{ Average Metal-H bond length (̊̊) } \\
\cline { 2 - 3 } & $\mathrm{Fe}-\mathrm{H}$ & $\mathrm{Ni}-\mathrm{H}$ \\
\hline $\mathrm{Fe}_{6}$ & 1.703 & 1.647 \\
\hline $\mathrm{Fe}_{5} \mathrm{Ni}_{1}$ & 1.700 & 1.605 \\
\hline $\mathrm{Fe}_{4} \mathrm{Ni}_{2}$ & 1.718 & 1.615 \\
\hline $\mathrm{Fe}_{3} \mathrm{Ni}_{3}$ & 1.712 & 1.618 \\
\hline $\mathrm{Fe}_{2} \mathrm{Ni}_{4}$ & 1.735 & 1.624 \\
\hline $\mathrm{Fe}_{1} \mathrm{Ni}_{5}$ & 1.758 & 1.634 \\
\hline $\mathrm{Ni}_{6}$ & & \\
\hline
\end{tabular}

Figure 6 displays the curves of the average $\mathrm{Fe}-\mathrm{H}$ and $\mathrm{Ni}-\mathrm{H}$ bonds length in different $\mathrm{Fe}_{\mathrm{x}} \mathrm{Ni}_{\mathrm{y}}$ clusters with the capacity of $12 \mathrm{H}$ atoms. The specific data is shown in Table 1. Zhou et al [26] reported that compare to the Pd-H bond lengths in Pd-based cluster (1.70-1.80 $\mathrm{A}$ ), the Ni-H bond lengths in Ni-based cluster are slightly shorter $\left(1.60-1.70 \AA\right.$ ). In the present study, the average $\mathrm{Fe}-\mathrm{H}$ bond lengths in $\mathrm{Fe}_{\mathrm{x}} \mathrm{Ni}_{\mathrm{y}}$ clusters are ranging from $1.69-1.76 \AA$, whereas the average $\mathrm{Ni}-\mathrm{H}$ bond lengths are within a relatively narrower range of 1.60-1.65 $\AA$. All the bond lengths undergo a change from decreasing to increasing. Especially, the average $\mathrm{Ni}-\mathrm{H}$ bond length of $\mathrm{Fe}_{4} \mathrm{Ni}_{2}$ cluster is close to the lowest value of $1.60 \AA$, indicating that $\mathrm{H}$ atoms on this cluster may be not easy to escape.

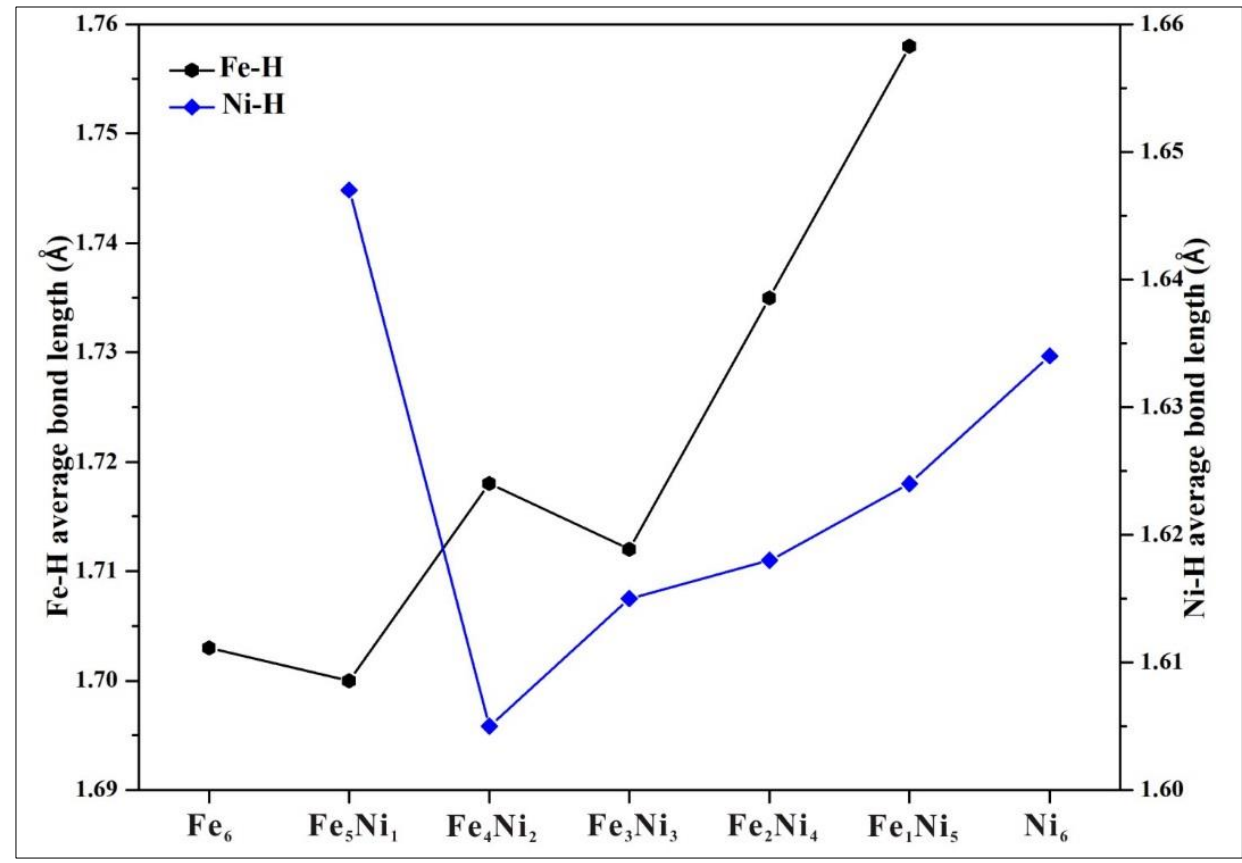

Figure 6. The average metal- $\mathrm{H}$ bond length of the $\mathrm{Fe}_{\mathrm{x}} \mathrm{Ni}_{\mathrm{y}}$ clusters

To compare variety of the calculated properties, Figure 7 shows the average formation energies of $\mathrm{Fe}_{x} \mathrm{Ni}_{y}$ clusters, the hydrogen chemisorption energies, the maximum hydrogen capacity as well as the hydrogen desorption energies on $\mathrm{Fe}_{x} \mathrm{Ni}_{y}$ clusters. The average formation energies of $\mathrm{Fe}_{x} \mathrm{Ni}_{y}$ clusters tend to be higher than that the corresponding $\mathrm{Fe}_{6}$ and $\mathrm{Ni}_{6}$ clusters (Figure 7a), suggesting that the configurations of bimetals are more stable than monometals during the hydrogen adsorption/desorption process. The hydrogen chemisorption energies (Figure 7b) of both $\mathrm{Fe}$ and Ni top sites vary within a small range of $0.27-0.58 \mathrm{eV}$, in which, $\mathrm{Fe}_{2} \mathrm{Ni}_{4}$ cluster has the highest value of $0.58 \mathrm{eV}$. Besides, the maximum hydrogen capacity also appears on $\mathrm{Fe}_{2} \mathrm{Ni}_{4}$ cluster (Figure 7c), indicating that it can load extra two hydrogen atoms compare to the other $\mathrm{Fe}_{x} \mathrm{Ni}_{y}$ clusters. The curve of hydrogen desorption energy exhibits a wave like tendency (Figure 7d), in which, $\mathrm{Fe}_{2} \mathrm{Ni}_{4}$ cluster possesses the lowest value of 1.98 $\mathrm{eV}$, while the $\mathrm{Fe}_{4} \mathrm{Ni}_{2}$ cluster shows a relatively higher $\Delta \mathrm{E}_{(\mathrm{DE})}$ of $2.23 \mathrm{eV}$. This result is in good agreement with the deduction obtained in Figure 6. Clearly, although bimetallization is helpful to the desorption of 
hydrogen atoms, it is still necessary to choose appropriate components to obtain an optimal catalytic performance. This is well agreed with a previous report [48] that a maximum activity for $25 \mathrm{Fe} 75 \mathrm{Ni}$ alloy on the catalytic $\mathrm{CO}$ hydrogenation. Based on these analyses, we can make a conclusion that a bimetal with an appropriate metal/metal ratio (e.g., $\mathrm{Fe}_{2} \mathrm{Ni}_{4}$ ) would help promoting the stability of its structure, increasing the hydrogen chemisorption energy, improving the capacity of hydrogen atoms and reducing the desorption energy of hydrogen, which could finally lead to the boost of its catalytic performance. On the other hand, an experimental study also proposed a possible mechanism for the promoted stability and efficient for the FeNi alloy, that adjacent nickel sites prevents the surface passivation of iron and in turn the iron sites donor electrons to the Ni sites to improve the activity [49].

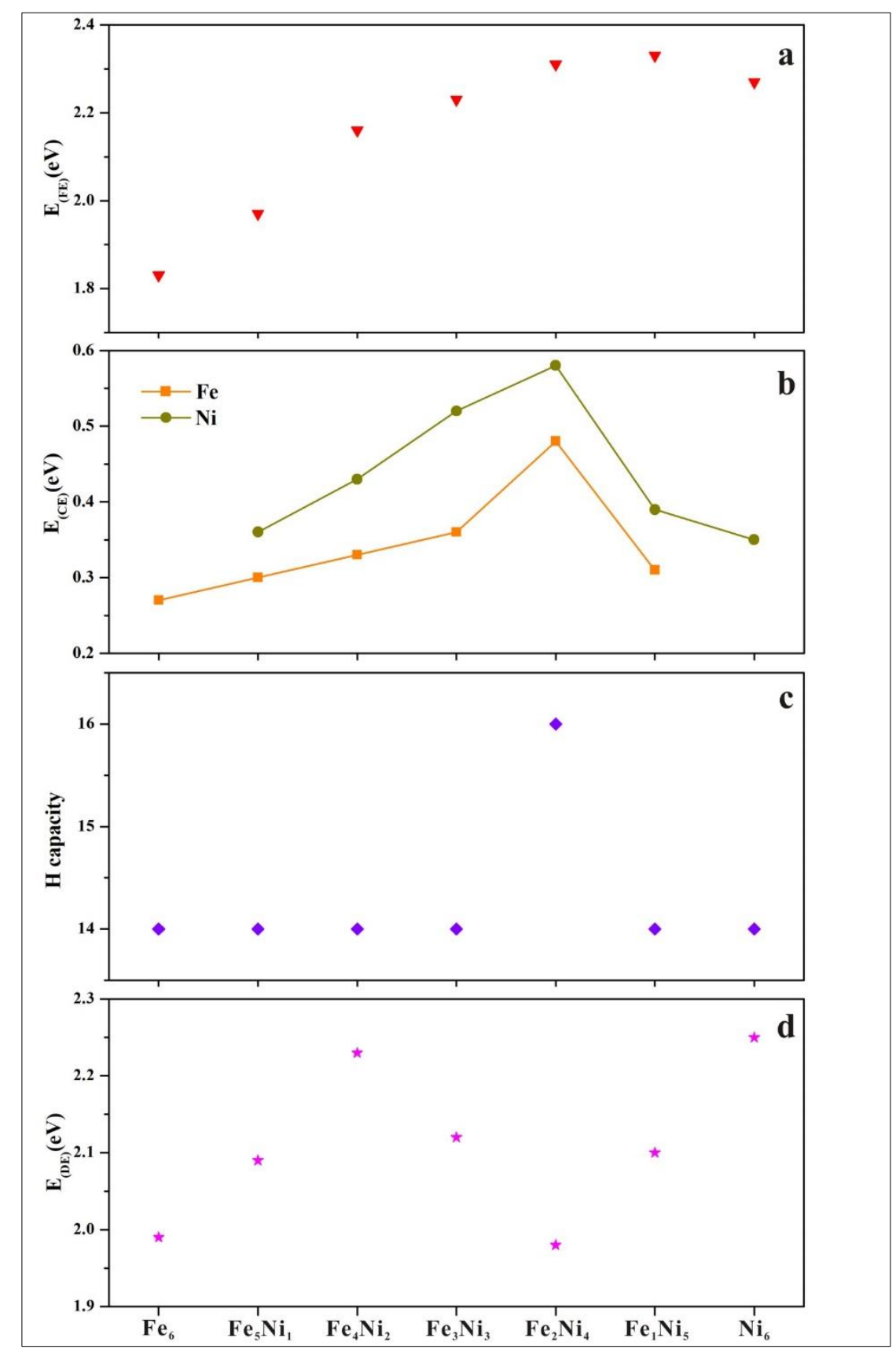

Figure 7. Comparison of $\mathrm{Fe}_{6}, \mathrm{Ni}_{6}$, and $\mathrm{Fe}_{x} \mathrm{Ni}_{y}(\mathrm{x}+\mathrm{y}=6)$ bimetallic clusters on (a) the average formation energies, (b) hydrogen chemisorption energies, (c) maximum hydrogen capacity, and (d) hydrogen desorption energies 


\section{Conclusions}

By performing massive minimum energy simulations, we explored the chemical properties of subnano $\mathrm{Fe}_{x} \mathrm{Ni}_{y}(\mathrm{x}+\mathrm{y}=6)$ bimetallic clusters. It is found that the interaction between $\mathrm{Fe}$ and $\mathrm{Ni}$ as well as the charge redistribution give rise to the structures of bimetallic clusters become more stable than pure $\mathrm{Fe}$ and $\mathrm{Ni}$ clusters. $\mathrm{Fe}_{x} \mathrm{Ni}_{y}$ bimetallic clusters have higher hydrogen chemisorption energies, this makes them more active in adsorbing and dissociating hydrogen. The reduced hydrogen desorption energies result in the readily release of hydrogen atoms from the cluster surface. The superior activity of $\mathrm{Fe}_{2} \mathrm{Ni}_{4}$ cluster implying that a bimetallic cluster with an appropriate metal/metal atomic ratio and charge distribution may obtain a remarkable promotion in the catalytic performance. We believe that the findings in this study could provide useful insights in understanding the interactions between different metals and adjust the constituents for the design of bimetals or even multi-metals, thereby shed light on the development of non-precious, environment friendly and highly effective nanoscale catalysts.

Acknowledgments. This work was supported by the Foundation of Equipment Project Management Center of China (No. 41421020501) and the National Natural Science Foundation of China (No. 21802129).

\section{References}

1. A. BIFFIS, M. ZECCA, M. BASATO, Palladium Metal Catalysts in Heck C-C Coupling Reactions. J. Mol. Catal. A: Chem. 2001, 173, 249-274.

2. D. ASTRUC, Palladium Nanoparticles as Efficient Green Homogeneous and Heterogeneous CarbonCarbon Coupling Pre catalysts: A Unifying View. Inorg. Chem. 2007, 46, 1884-1894.

3. R.C. LAROCK, X.Y. DONG, S. CHUNG, C.K. REDDY, L.E. EHLERS, Preparation of Conjugated Soybean Oil and Other Natural Oils and Fatty Acids by Homogeneous Transition Metal Catalysis. J. Am. Oil Chem. Soc. 2001, 78, 447-453.

4. J. MUSLEHIDDINOGLU, J. LI, S. TUMMALA, R. DESHPANDE, Highly Diastereoselective Hydrogenation of Imines by a Bimetallic Pd-Cu Heterogeneous Catalyst. Org. Process Res. Dev. 2010, 14, 890-894.

5. W.L. ZHANG, W.X. SHI, W.L. JI, H.B. WU, Z.D. GU, P. WANG, X.H. LI, P.S. QIN, J. ZHANG, Y. FAN, Microenvironment of MOF Channel Coordination with Pt NPs for Selective Hydrogenation of Unsaturated Aldehydes. ACS CATAL. 2020, 10, 5805-5813.

6. C. BREINLICH, J. HAUBRICH, C. BECKER, A. VALCARCEL, F. DELBECQ, K. WANDELT. Hydrogenation of 1,3-Butadiene on $\mathrm{Pd}(111)$ and $\mathrm{PdSn} / \mathrm{Pd}(111)$ Surface Alloys under UHV Conditions. J. Catal. 2007, 251, 123-130.

7. T. ISHIHARA, A. KAWAHARA, A. FUKUNAGA, H. NISHIGUCHI, H. SHINKAI, M. MIYAKI, Y. TAKITA. CH4 Decomposition with a $\mathrm{Pd}-\mathrm{Ag}$ Hydrogen-Permeating Membrane Reactor for Hydrogen Production at Decreased Temperature. Ind. Eng. Chem. Res. 2002, 41, 3365-3369.

8. D. TAKEUCHI, A. INOUE, F. ISHIMARU, K. OSAKADA. Living Ring Opening Polymerization of 2-Alkoxy-1-methylenecyclopropanes Initiated by Pd Complexes. Macromolecules. 2008, 41, 6339-6346.

9. L.H. LU, Z.M. RONG, W.Q. DU, S.H. MA, S. HU. Selective Hydrogenation of Single Benzene Ring in Biphenyl Catalyzed by Skeletal Ni. CHEMCATCHEM. 2009, 1,369-371.

10.M.K. OUDENHUIJZEN, J.A. BOKHOVEN, J.T. MILLER, D.E. RAMAKER, D.C. KONINGSBERGER. Three-Site Model for Hydrogen Adsorption on Supported Platinum Particles: Influence of Support Ionicity and Particle Size on the Hydrogen Coverage. J. Am. Chem. Soc. 2005, 127, 1530-1540.

11.S.P. PATIL, J.V. PANDE, R.B. BINIWALE. Non-noble Ni-Cu/ACC bimetallic catalyst for dehydrogenation of liquid organic hydrides for hydrogen storage. Int. J. Hydrogen Energy. 2013, 38, 15233-15241. 
12. C.Y. WANG, L.L. LI, X.F. YU. Regulation of d-Band Electrons to Enhance the Activity of CoBased Non-Noble Bimetal Catalysts for Hydrolysis of Ammonia Borane. ACS SUSTAIN. CHEM. ENG. 2020, 8, 8256-8266

13. Y.Y. ZHAI, M.Z. CHU, N.Z. SHANG, Bimetal Co8Ni2 catalyst supported on chitin-derived Ncontaining carbon for upgrade of biofuels. APPL. SURF. SCI. 2020, 506,144681

14. S. SINGH, R.K. GAUTAM, K. MALIK. Ag-Co bimetallic catalyst for electrochemical reduction of CO2 to value added products. J. CO2 UTIL. 2017, 18, 139-146.

15. W. XU, D.W. DU, R. LAN. Electrodeposited NiCu bimetal on carbon paper as stable nonnobleanode for efficient electrooxidation of ammonia. APPL. CATAL. B-ENVIRON. 2018, 237,11011109

16. H.X. JIA, M.Z. ZHANG, T.J. MENG. Facile synthesis of Fe, Co bimetal embedded nanoporous carbon polyhedron composites for an efficient oxygen evolution reaction. J. COLLOID. INTERF. SCI. 2020, $563,189-196$

17. S.J. CHO, H.B NOH, M.S. WON. A selective glucose sensor based on direct oxidation on a bimetal catalyst with a molecular imprinted polymer. BIOSENS. BIOELECTRON. 2018, 99, 471-478 .

18. L.Q. LI, H.J. ZHENG, L.L. GUO. Construction of novel electrochemical sensors based on bimetallic nanoparticle functionalized graphene for determination of sunset yellow in soft drink. J. ELECTROANAL. CHEM. 2019, 833, 393-400

19. L.C. WANG, C.Y. HOU, H. YU. Metal-Organic Framework-Derived Nickel/Cobalt-Based Nanohybrids for Sensing NonEnzymatic Glucose. CHEMELECTROCHEM. 2020, 7, 4446-4452

20. D. PANDEY, G. DEO. Promotional effects in alumina and silica supported bimetallic Ni-Fe catalysts during CO2 hydrogenation. J. MOL. CATAL. A-CHEM. 2014, 382, 23-30.

21. V.A. CASTILLO; J.N. KUHN. Role of the Ni:Fe Ratio in Ethylene Hydrogenation Activity for Silica-Supported Ni-Fe Clusters Prepared by Dendrimer-Templating. J. Phys. Chem. C. 2012, 116, 8627-8633.

22. B.C. QIU, L.J. CAI, Y. WANG. Fabrication of Nickel-Cobalt Bimetal Phosphide Nanocages for Enhanced Oxygen Evolution Catalysis. ADV. FUNCT. MATER. 2018, 28,1706008.

23. Z.J. WANG, C.X. WANG, S.Q. CHEN. Co-Ni bimetal catalyst supported on perovskite-type oxide for steam reforming of ethanol to produce hydrogen. INT. J. HYDROGEN ENERG. 2014, 39, 5644-5652

24. L.C. LIU, F. GAO, P. CONCEPCION, A. CORMA. A new strategy to transform mono and bimetallic non-noble metal nanoparticles into highly active and chemoselective hydrogenation catalysts. J. CATAL.2017, 350, 218-225.

25. K.V. MANUKYAN, A. CROSS, S. ROUVIMOV. Low temperature decomposition of hydrous hydrazine over FeNi/Cu nanoparticles. APPL. CATAL. A-GEN. 2014, 476, 47-53

26. C. ZHOU, S. YAO, Q. ZHANG, J. WU, M. YANG. R.C. FORREY, H.S. CHENG. Hydrogen Sequential Dissociative Chemisorption on $\mathrm{Ni} \mathrm{N}(\mathrm{N}=2-9,13)$ Clusters: Comparison with Pt and Pd. J. Mol. Model. 2011, 17, 2305-2311.

27. I. SWART, F.M.F DE GROOT, B.M. WECKHUYSEN, P. GRUENE, G. MEIJER, A. FIELICKE, H2 Adsorption on 3d Transition Metal Clusters: A Combined Infrared Spectroscopy and Density Functional Study. J. Phys. Chem. A. 2008, 112, 1139-1149.

28. C. ASHMAN, S.N. KHANNA, M.R. PEDERSON. Hydrogen Absorption and Magnetic Moment of Nin Clusters. Chem. Phys. Lett. 2003, 368, 257-261.

29. H. FRANK, W. JOSEPH, D. MCGREGOR, G.E. LOPEZ. The'Electronic Structures of NickelPalladium Alloy Clusters: A Density Functional Theory Study. Chem. Lett. 2018, 47, 458-460.

30.E.M. SOSA-HERNANDEZ, J.M. MONTEJANO-CARRIZALES, P.G. ALVARADO-LEYVA. Global Minimum Structures, Stability and Electronic Properties of Small Ni X Sn Y $(X+Y \leqslant 5)$ Bimetallic Clusters; a DFT Study. Eur. Phys. J. 2016, 70, 208. 
31.R.K. SINGH, T. IWASA, T. TAKETSUGU. Insights into geometries, stabilities, electronic structures, reactivity descriptors, and magnetic properties of bimetallic $\mathrm{Ni} \mathrm{m} \mathrm{Cu} \mathrm{n-m}(\mathrm{m}=1,2 ; \mathrm{n}=3$ 13) clusters: Comparison with pure copper clusters. J. Comput. Chem. 2018, 39, 1878-1889.

32.M. BENAIDA, K. AIADI, S. MAHTOUT, S. DJAADI, W. RAMMAL, M. HARB. Growth Behavior and Electronic Properties of Ge N+1 and Asge N (N=1-20) Clusters: A DFT Study. J. Semicond. 2019, 40, 032101.

33. M. JIA, J. VANBUEL, P. FERRARI, E.M. FERNÁNDEZ, S. GEWINNER, W. SCHÖLLKOPF, M.T. NGUYEN, A. FIELICKE, E. JANSSENS. Size Dependent H2 Adsorption on AlnRh+ $(\mathrm{n}=1-12)$ Clusters. J. Phys. Chem. C 2018, 122, 18247-18255.

34. M. SAMADIZADEH, A.A. PEYGHAN, S.F. RASTEGAR. DFT Studies of Hydrogen Adsorption and Dissociation on Mgo Nanotubes. Main Group Chem. 2016, 15, 107-116.

35. I. YAROVSKY, A. GOLDBERG. DFT study of hydrogen adsorption on Al13 clusters. Mol. Simul. 2005, 31, 475-481.

36. B. DELLEY. Fast Calculation of Electrostatics in Crystals and Large Molecules. J. Phys. Chem. A. 1996, 100, 6107-6110.

37. B. DELLEY. From molecules to solids with the DMol3 approach. J. Chem. Phys. 2000, 113, 7756-7764.

38. M. DOLG, U. WEDIG, H. STOLL, H. PREUSS. Energy-adjusted ab initio pseudo potentials for the first row transition elements. J. Chem. Phys. 1987, 86, 866-872.

39.A. BERGNER, M. DOLG, W. KÜCHLE, H. STOLL, H. PREUß. Ab initio energy-adjusted pseudopotentials for elements of groups 13-17. Mol. Phys. 1993, 80, 1431-1441.

40.B. DELLEY. An all-electron numerical method for solving the local density functional for polyatomic molecules. J. Chem. Phys. 1990, 92, 508-517.

41.A. TKATCHENKO, M. SCHEFFLER. Accurate Molecular Van Der Waals Interactions from Ground-State Electron Density and FreeAtom Reference Data. Phys. Rev. Lett. 2009, 102, 073005.

42.T.A. HALGREN, W.N. LIPSCOMB. The Synchronous-Transit Method for Determining Reaction Pathways and Locating Molecular Transition States. Chem. Phys. Lett. 1977, 49, 225-232.

43.S.A. NOSE. Unified Formulation of the Constant Temperature Molecular Dynamics Methods. J. Chem. Phys. 1984, 81, 511-519.

44. G.J. MARTYNA, M.E. TUCKERMAN, D.J. TOBIAS, M.L. KLEIN. Explicit Reversible Integrators for Extended Systems Dynamics. Mol. Phys. 1996, 87, 1117-1157.

45. G. PSOFOGIANNAKIS, A. ST-AMANT, M. TERNAN. Methane Oxidation Mechanism on Pt(111): A Cluster Model DFT Study. J. Phys. Chem. B 2006, 110, 24593-24605.

46. I. UDREA, E. GRONER, L. FRUNZA. $\mathrm{Al}_{2} \mathrm{O}_{3}$-supported Fe-Ni Catalysts for CO Hydrogenation, I. Catalytic Properties. React. Kinet. Catal. Lett. 1994, 53, 451-458.

47. S.X. FEI, B. HAN, Q.F. ZHANG, M. YANG, H.S. CHENG. Density Functional Theory Study on the Role of Polyacetylene as a Promoter in Selective Hydrogenation of Styrene on a Pd Catalyst. J. Phys. Chem. C. 2017, 121, 4246-4252.

48. T. ISHIHARA, K. EGUCHI, H. ARAI. Hydrogenation of Carbon Monoxide over $\mathrm{SiO}_{2}$-supported Fe-Co, Co-Ni and Ni-Fe bimetallic catalysts. Appl. Catal. 1987, 30, 225-238.

49. DHANANJAY R. PETKAR, BRIJESH S. KADU AND RAJEEV C. CHIKATE, Highly efficient and chemoselective transfer hydrogenation of nitroarenes at room temperature over magnetically separable Fe-Ni bimetallic nanoparticles. RSC Adv. 2014, 4, 8004-8010.

$\overline{\text { Manuscript received: } 01.04 .2021}$ 